\title{
Pressure effect on crystallization of metallic glass Fe72P11C6AI5B4Ga2 alloy with wide supercooled liquid region
}

Jiang, Jianzhong; Olsen, J. S.; Gerward, Leif; Abdali, Salim; Eckert, J.; Schlorke, L.; Schultz, L.; Truckenbrodt, J.; Shi, Peixiong

Published in:

Journal of Applied Physics

Link to article, DOI:

10.1063/1.372237

Publication date:

2000

Document Version

Publisher's PDF, also known as Version of record

Link back to DTU Orbit

Citation (APA):

Jiang, J., Olsen, J. S., Gerward, L., Abdali, S., Eckert, J., Schlorke, L., Schultz, L., Truckenbrodt, J., \& Shi, P. (2000). Pressure effect on crystallization of metallic glass Fe72P11C6Al5B4Ga2 alloy with wide supercooled liquid region. Journal of Applied Physics, 87(5), 2664-2666. https://doi.org/10.1063/1.372237

\section{General rights}

Copyright and moral rights for the publications made accessible in the public portal are retained by the authors and/or other copyright owners and it is a condition of accessing publications that users recognise and abide by the legal requirements associated with these rights.

- Users may download and print one copy of any publication from the public portal for the purpose of private study or research.

- You may not further distribute the material or use it for any profit-making activity or commercial gain

- You may freely distribute the URL identifying the publication in the public portal 


\title{
Pressure effect on crystallization of metallic glass $F e_{72} P_{11} C_{6} A I_{5} B_{4} G_{2}$ alloy with wide supercooled liquid region
}

\author{
J. Z. Jiang ${ }^{a)}$ \\ Department of Physics, Building 307, Technical University of Denmark, DK-2800 Lyngby, Denmark \\ J. S. Olsen \\ Niels Bohr Institute, Oersted Laboratory, DK-2100 Copenhagen, Denmark \\ L. Gerward and S. Abdali \\ Department of Physics, Building 307, Technical University of Denmark, DK-2800 Lyngby, Denmark \\ J. Eckert, N. Schlorke-de Boer, and L. Schultz \\ IFW Dresden, Institut für Metallische Werkstoffe, Postfach 270016, D-01171 Dresden, Germany \\ J. Truckenbrodt \\ HASYLAB am DESY, Notkestrasse 85, D-22603 Hamburg, Germany \\ P. X. Shi \\ Mikroelektronik Centret, Building 345, Technical University of Denmark, DK-2800 Lyngby, Denmark
}

(Received 2 June 1999; accepted for publication 13 October 1999)

The effect of pressure on the crystallization behavior of metallic glass $\mathrm{Fe}_{72} \mathrm{P}_{11} \mathrm{C}_{6} \mathrm{Al}_{5} \mathrm{~B}_{4} \mathrm{Ga}_{2}$ alloy with a wide supercooled liquid region has been investigated by in situ high-pressure and high-temperature $\mathrm{x}$-ray diffraction measurements using synchrotron radiation. In the pressure range from 0 to $2.4 \mathrm{GPa}$, the crystallization temperature, $T_{x}$, increases with pressure, $p$, having a slope of $30 \mathrm{~K} / \mathrm{GPa}$ while a minimum in $T_{x}$ was detected in the range from 2.4 to $3.9 \mathrm{GPa}$. With a further increase of $p, T_{x}$ is independent of $p$. The $T_{x}$ vs $p$ behavior can be qualitatively explained by the suppression of atomic mobility and changes of the Gibbs free energy of various phases with pressure. (C) 2000 American Institute of Physics. [S0021-8979(00)01902-2]

Recently, Inoue et al. ${ }^{1}$ found that $\mathrm{Fe}-\mathrm{Al}-\mathrm{P}-\mathrm{C}-\mathrm{B}-\mathrm{Ga}$ alloys have wide supercooled liquid regions and good soft magnetic properties. The large glass forming ability of this alloy system enables the formation of bulk glassy samples with diameters up to $1 \mathrm{~mm}$ by slow cooling. Such samples have a coercive force down to $12.7 \mathrm{~A} / \mathrm{m}$ and a saturation magnetization up to $1.07 \mathrm{~T}$, promising future use as a new soft magnetic material. ${ }^{2}$ However, the magnetic properties of metallic glasses are highly sensitive to small amounts of crystalline material. Thus, the danger of using them without detailed knowledge of their crystallization process cannot be overstressed. In general, metallic glasses possess a few percent of free volume. The crystallization of metallic glasses is accompanied by a densification of about a few percent. $^{3}$ Thus, one might expect that external pressure would accelerate the crystallization process since the metallic glass can be densified by the applied pressure. In this work we report the pressure effect on the crystallization for a Fe-based metallic glass alloy with a wide supercooled liquid region.

$\mathrm{Fe}_{72} \mathrm{P}_{11} \mathrm{C}_{6} \mathrm{Al}_{5} \mathrm{~B}_{4} \mathrm{Ga}_{2}$ ribbons with a width of about 10 $\mathrm{mm}$ and a thickness of about $25 \mu \mathrm{m}$ were prepared by the melt-spinning technique. Thermal analysis was performed in a Perkin-Elmer DSC 7 differential scanning calorimeter (DSC) at a heating rate of $40 \mathrm{~K} / \mathrm{min}$ under a flow of purified argon. It was found that the glass transition temperature is $T_{g}=743 \mathrm{~K}$, the crystallization temperature is $T_{x}=798 \mathrm{~K}$ and

\footnotetext{
a)Electronic mail: jiang@fysik.dtu.dk
}

$\Delta T=T_{x}-T_{g}=55 \mathrm{~K}$. In situ high-pressure and hightemperature energy-dispersive $\mathrm{x}$-ray diffraction (EDXRD) measurements were performed using synchrotron radiation by the MAX80 station at HASYLAB in Hamburg, Germany. Each run consists of isothermal room-temperature compression followed by isobaric heating to high temperature. The pressure, $p$, of the sample $(<6 \mathrm{GPa})$ is calculated from the lattice constant of $\mathrm{NaCl}$ using the Decker equation of state. ${ }^{4}$ In addition, we have also carried out room-temperature compression EDXRD measurements up to $35 \mathrm{GPa}$ using a diamond-anvil cell by the F3 station at HASYLAB. A pressure transmitting medium of 4:1 methanol:ethanol solution was used. The actual pressure was calculated from the wavelength shift of the ruby line using the nonlinear pressure scale of Mao et al. ${ }^{5}$ For crystalline phase identification standard x-ray powder diffraction using $\mathrm{Cu} K \alpha$ radiation as well as Mössbauer spectroscopy measurements at ambient temperature and pressure were performed in the samples which were isochronally annealed in a vacuum of $3 \times 10^{-5} \mathrm{~Pa}$ at various temperatures for $1 \mathrm{~h}$.

A large number of EDXRD patterns of the metallic glass were recorded at pressures ranging from 0 to approximately $35 \mathrm{GPa}$ at room temperature. Up to a pressure of approximately $35 \mathrm{GPa}$, no crystalline phase was observed. The position of the main peak was found to increase with pressure. This means that the corresponding $d$ spacing decreases with pressure. If one assumes that the density of the amorphous alloy is proportional to $1 / d^{3}$, one can estimate the ratio of the 


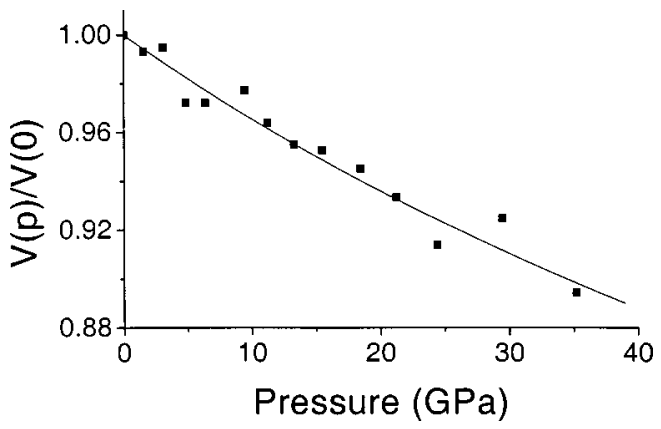

FIG. 1. Compression data of the $\mathrm{Fe}_{72} \mathrm{P}_{11} \mathrm{C}_{6} \mathrm{Al}_{5} \mathrm{~B}_{4} \mathrm{Ga}_{2}$ metallic glass at room temperature. The solid curve is calculated from the Birch equation of state.

volume at a given pressure to that at zero pressure, $V(p) / V(0)$, of the metallic glass, as shown in Fig. 1. The volume ratio decreases monotonically with pressure. At approximately $35 \mathrm{GPa}$, the metallic glass has contracted by approximately $10 \%$. The pressure-volume data shown in Fig. 1 have subsequently been fitted to the Birch equation of state. $^{6}$ The zero-pressure bulk modulus is found to be $265 \pm 10 \mathrm{GPa}$, which is much larger than that for bodycentered-cubic bcc iron, $170 \pm 5 \mathrm{GPa}^{7}$

Figure 2 exemplifies EDXRD patterns recorded for crystallized samples at various pressures. The phases, $A 1, A 2$, and $A 3$, will be explained below. Figure 3 shows the crystallization temperature, which was estimated from EDXRD patterns recorded by increasing temperature with a stepsize of about $10 \mathrm{~K}$ as a function of pressure. It is clearly seen that the applied pressure strongly affects the crystallization temperature of the Fe-based metallic glass, and that the behavior of $T_{x}$ vs $p$ differs in various pressure ranges. From 0 to 2.4 $\mathrm{GPa}, T_{x}$ increases with pressure, having a slope of $30 \mathrm{~K} / \mathrm{GPa}$. This value is larger than those reported for metallic glasses with no wide supercooled liquid range, where $d T_{x} / d p$ $\sim 0-20 \mathrm{~K} / \mathrm{GPa}^{8-14}$ In the range from 2.4 to $3.9 \mathrm{GPa}$, a minimum in $T_{x}$ was detected at a pressure of $3.2 \mathrm{GPa}$. With a further increase of pressure, the $T_{x}$ is independent of the external pressure. In order to understand these differences in the $T_{x}$ vs $p$ behavior, crystalline phase identification in crys-

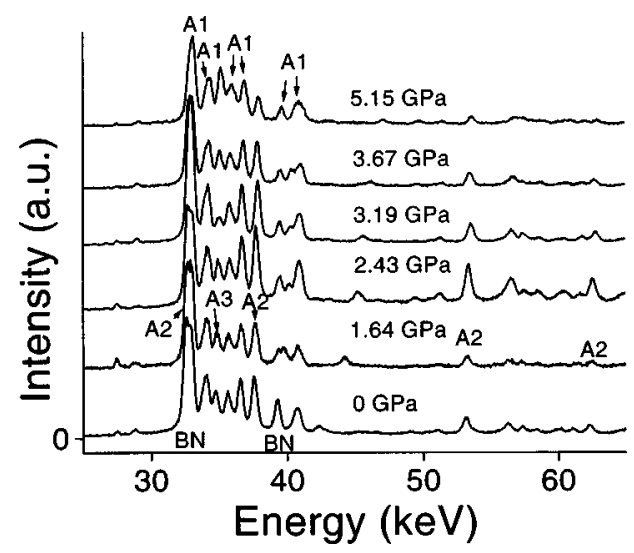

FIG. 2. Energy-dispersive $\mathrm{x}$-ray diffraction patterns recorded for crystallized samples at various pressures. Notations $A 1, A 2$, and $A 3$ refer to three crystalline phases. Some diffraction peaks of boron nitride originating from the sample holder are marked by BN.

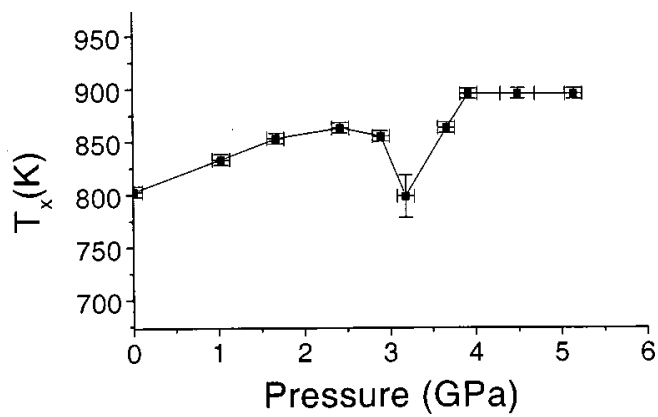

FIG. 3. Crystallization temperature of the $\mathrm{Fe}_{72} \mathrm{P}_{11} \mathrm{C}_{6} \mathrm{Al}_{5} \mathrm{~B}_{4} \mathrm{Ga}_{2}$ metallic glass as a function of pressure. The solid line is a guide for the eye.

tallized samples at various pressures is essential. Due to the poor resolution in the EDXRD measurements and the fact that several phases exist in the crystallized samples, we first attempt to identify the crystalline phases in samples annealed in vacuum by using standard X-ray powder diffraction (XRD) and Mössbauer spectroscopy (MS) at ambient temperature and pressure. Figure 4 exemplifies an XRD pattern and a MS spectrum of a sample annealed at $823 \mathrm{~K}$. Three crystalline phases were identified from the XRD and MS measurements in the annealed samples. They are (1) a phase (marked $A 1$ ) with a $\mathrm{Ni}_{3} \mathrm{P}$-like tetragonal structure ${ }^{15}$ (space group: I4) having lattice constants of $a=8.93 \AA$ and $c$ $=4.41 \AA$ and a composition close to $\mathrm{Fe}_{3}(\mathrm{M})$, where $\mathrm{M}$ stands for P, C, Al, B, and Ga elements; (2) a phase (marked $A 2$ ) with a $\mathrm{Fe}_{3}(\mathrm{NiN})_{2}$-like cubic structure ${ }^{15}$ (space group: $P m 3 \mathrm{~m}$ ) having a lattice constant of $a=3.78 \AA$ and a com-
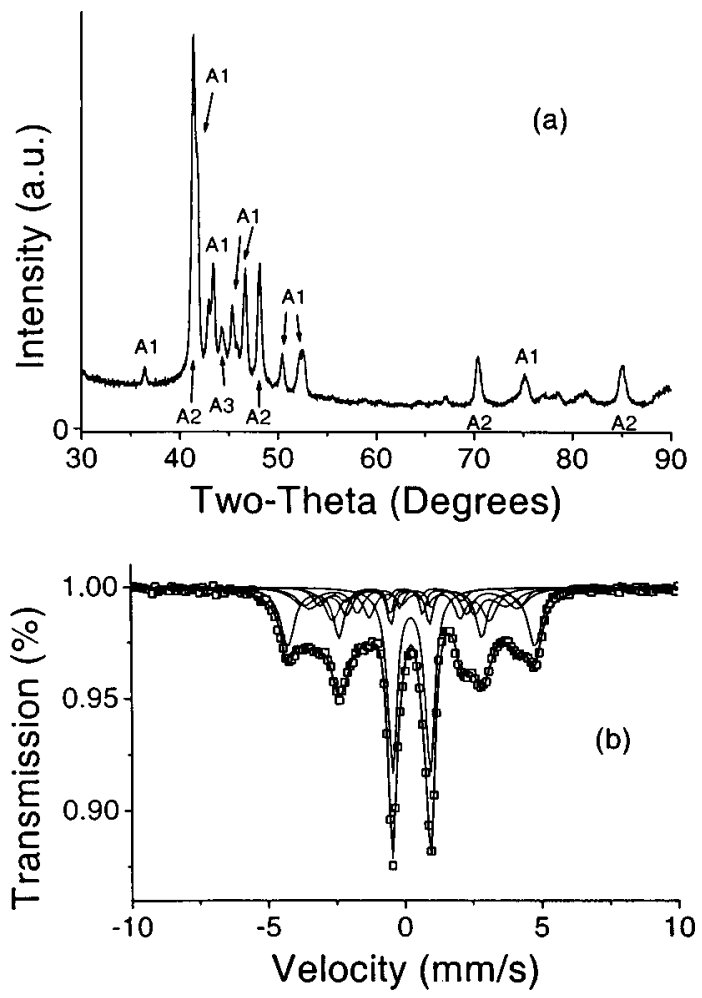

FIG. 4. (a) X-ray powder diffraction pattern and (b) Mössbauer spectrum recorded at $295 \mathrm{~K}$ for the sample annealed at $823 \mathrm{~K}$ in a vacuum of 3 $\times 10^{-5} \mathrm{~Pa}$ for $1 \mathrm{~h}$. Notations $A 1, A 2$, and $A 3$ refer to three crystalline phases. The solid lines in (b) are fitting curves. 
position close to $\mathrm{Fe}_{3}(\mathrm{M})_{2}$; and (3) a phase (marked A3) with a $\mathrm{Fe}_{23}(\mathrm{CB})_{6}$-like cubic structure ${ }^{15}$ (space group: $\mathrm{Fm} 3 \mathrm{~m}$ ) having a lattice constant of $a=10.6 \AA$ and a composition close to $\mathrm{Fe}_{23}(\mathrm{M})_{6}$. From the XRD and MS investigations of samples annealed at various temperatures, it is found that the crystallization process of the metallic glass Fe-based alloy in vacuum is characteristic of a three-phase eutectic reaction. Second, we compared the $d$ spacings of the three phases with the EDXRD data and found that the diffraction peaks in the EDXRD patterns recorded from the crystallized samples under various pressures can be attributed to the three crystalline phases. The relative amounts of the three phases could be different in crystallized samples at various pressures.

In general, applied pressure on metallic glasses might have three effects. The first effect is densification, which reduces the free volume in the glass by pressure. This effect could favor the crystallization process because crystallization of metallic glasses involves densification. The second effect is suppression of atomic mobility at high pressures, which reduces the atomic diffusion in metallic glasses. At least for eutectic or primary crystallization processes this effect retards crystallization since atomic diffusion is required for these crystallization processes. The third effect is due to changes in relative Gibbs free energies of the glassy phase and crystalline phases by pressure, and in the energy barrier for crystallization. This effect could alter the relative amounts of the crystalline phases in the crystallized samples, and could be of either sign with regard to $d T_{x} / d p$.

Figure 1 reveals that no crystallization occurs at $295 \mathrm{~K}$ in the sample upon a volume reduction of approximately $10 \%$ which is much larger than the free volumes (of usually a few percent) reported for metallic glasses. ${ }^{3}$ For the bulk glass forming $\mathrm{MgYCu}$ system the amorphous state still remains in the sample for approximately $30 \%$ contraction in volume. ${ }^{16}$ These results suggest that densification induced by external pressure does not have any important influence on the crystallization temperature of these metallic glass systems with a wide supercooled liquid region. The crystallization process in the pressure range from 0 to $1.6 \mathrm{GPa}$ is found to be similar, generating three phases $(A 1, A 2$, and $A 3)$. For the eutectic reaction, a redistribution of atoms (or atomic diffusion) is necessary. Due to the second effect mentioned above, pressure prevents crystallization so that a higher crystallization temperature is expected. This explains the observed increase in $T_{x}$ with pressure in the range from 0 to 1.6 $\mathrm{GPa}$ in Fig. 3. At $3.2 \mathrm{GPa}$, the minimum in $T_{x}$ could be linked with the fact that the relative amount of $A 3$ phase is very small in the crystallized sample. The pressure here affects the relative amounts of three crystalline phases in the crystallized samples. It is not unreasonable to expect less difficulty to crystallize the glass into mainly two phases than into three phases. This implies that the third effect mentioned above may accelerate the crystallization. Further work is still required to understand the mechanism for the minimum in
$T_{x}$. With increasing pressure, the amount of $A 3$ phase increases so that the crystallization process of the sample again involves a three-phase eutectic reaction. $T_{x}$ increases accordingly with pressure in the range from 3.2 to $3.9 \mathrm{GPa}$. At still higher pressures $(>3.9 \mathrm{GPa})$, a remarkable enhancement of the $A 3$ phase is found in the crystallized samples while the relative amount of $A 2$ phase decreases and the $A 1$ phase remains almost unchanged. Hence, two competing effects (the second and third pressure effects) yield a saturated crystallization temperature within the pressure range from 3.9 to $5.2 \mathrm{GPa}$.

In conclusion, the effect of pressure on the crystallization processes of the metallic glass $\mathrm{Fe}_{72} \mathrm{P}_{11} \mathrm{C}_{6} \mathrm{Al}_{5} \mathrm{~B}_{4} \mathrm{Ga}_{2}$ alloy with a wide supercooled liquid region has been investigated by in situ high-pressure and high-temperature x-ray diffraction measurements using synchrotron radiation. It was found that the external pressure can strongly influence the crystallization temperature of the metallic glass. The behavior of $T_{x}$ vs $p$ is mainly governed by the suppression of atomic mobility and changes in relative Gibbs free energy of various phases with pressure. The densification effect induced by pressure only plays a minor role in the crystallization behavior of this alloy.

The authors thank HASYLAB in Hamburg for use of the synchrotron radiation facilities. They are indebted to $\mathrm{S}$. Mbrup for fruitful discussions. Financial support from the Danish Technical Research Council and from the Danish Natural Sciences Research Council is gratefully acknowledged.

${ }^{1}$ A. Inoue and J. S. Gook, Mater. Trans., JIM 36, 1180 (1995); 36, 1282 (1995).

${ }^{2}$ A. Inoue, Y. Shinohara, and J. S. Gook, Mater. Trans., JIM 36, 1427 (1995); A. Inoue, A. Makino, and T. Mizushima, J. Appl. Phys. 81, 4029 (1997).

${ }^{3}$ H. S. Chen, J. Appl. Phys. 49, 3289 (1978).

${ }^{4}$ D. L. Decker, J. Appl. Phys. 42, 3239 (1971).

${ }^{5}$ H. K. Mao, P. M. Bell, J. W. Shaner, and D. J. Steinberg, J. Appl. Phys. 49, 3276 (1978).

${ }^{6}$ F. Birch, J. Appl. Phys. 9, 279 (1938); Phys. Rev. 71, 809 (1947).

${ }^{7}$ J. Z. Jiang, J. S. Olsen, L. Gerward, and S. Mørup, Nanostruct. Mater. 12, 847 (1999).

${ }^{8}$ W. Emmens, J. Vrijen, and S. Radelaar, J. Non-Cryst. Solids 18, 299 (1975).

${ }^{9}$ H. Iwasaki and T. Masumoto, J. Mater. Sci. 13, 2171 (1978).

${ }^{10}$ M. Cedergren and G. Backstrom, J. Non-Cryst. Solids 30, 69 (1978).

${ }^{11}$ W. K. Wang, H. Iwasaki, and K. Fukamichi, J. Mater. Sci. 15, 2701 (1980).

${ }^{12}$ C. Suryanarayana, W. K. Wang, H. Iwasaki, and T. Masumoto, Solid State Commun. 34, 861 (1980).

${ }^{13}$ W. K. Wang, H. Iwasaki, C. Suryanarayana, and T. Masumoto, J. Mater. Sci. 18, 3765 (1983).

${ }^{14}$ T. Imura, M. Suwa, and K. Fujii, Mater. Sci. Eng. 97, 247 (1988).

${ }^{15}$ The JCPDS cards are 14-212 for the $\mathrm{Ni}_{3} \mathrm{P}$ structure, 9-318 for the $\mathrm{Fe}_{3}(\mathrm{NiN})_{2}$ structure, and $12-570$ for the $\mathrm{Fe}_{23}(\mathrm{CB})_{6}$ structure, published by the International Center for Diffraction Data, 1601 Park Lane Swarthmore, PA 19081

${ }^{16}$ J.Z. Jiang, J.S. Olsen, L. Gerward, J. Eckert, N. Schlorke, L. Schultz, and J. Truckenbrodt (unpublished). 